\title{
COMUNICAÇÃO
}

\section{INFLUÊNCIA DE SAFRAS AGRÍCOLAS E TRATAMENTOS FUNGICIDAS NO CAFÉ CEREJA DESCASCADO E BÓIA ${ }^{1}$}

\author{
Influence of harvests and fungicide treatments on the parchment and floaters coffee
}

\author{
Adriano Andrade Abrahão ${ }^{2}$, Rosemary Gualberto Fonseca Alvarenga Pereira ${ }^{3}$, \\ Flávio Meira Borém ${ }^{4}$, Juliana Costa de Rezende ${ }^{5}$, José Carlos Barbosa ${ }^{6}$
}

\begin{abstract}
RESUMO
O manejo adequado de doenças foliares, como a ferrugem e a cercosporiose do cafeeiro, é fator primordial para a produção de bebidas de qualidade. Nesse sentido, torna-se de extrema importância o conhecimento dos procedimentos técnicos e de produtos fitossanitários, bem como o efeito exercido pelos mesmos na qualidade do café. Objetivou-se, com este trabalho, estudar a qualidade dos grãos de café cereja descascado e bóia procedentes de tratamentos fungicidas, em duas safras agrícolas. Foram conduzidos ensaios nos anos agrícolas 2002/03 e 2003/04. O delineamento utilizado foi o inteiramente casualizado com parcelas subdivididas, utilizandose quatro repetições, em esquema fatorial $2 \times 3 \times 2$, compreendendo duas safras, três tratamentos fungicidas (fungicida sistêmico, nome comercial Opera ${ }^{\circledR}$, fungicida de contato, nome comercial Cobox ${ }^{\circledR}$, e testemunha não tratada com fungicidas) e dois tipos de processamento, cereja descascado e bóia. As avaliações da qualidade dos grãos foram realizadas por meio das análises químicas: acidez titulável, pH, lixiviação de potássio e condutividade elétrica. Os resultados indicaram que os tratamentos fungicidas afetaram apenas a lixiviação de potássio para o café bóia, no qual o Cobox ${ }^{\circledR}$ apresentou menor lixiviação comparado aos demais. Em ambos os processamentos estudados, o segundo ano de ensaio apresentou maior condutividade elétrica, e quando considerado o café bóia, maior lixiviação de potássio. O resultados apontam ainda que, no primeiro ano de ensaio o café cereja descascado apresentou efeito superior para a acidez titulável.
\end{abstract}

Termos para indexação: Coffea arabica L., qualidade, manejo.

\begin{abstract}
The appropriate management of leaf diseases, such as rust and cercospora of the coffee plant, has become extremely important to the production of good quality coffee. In this context, the knowledge of technical procedures and phytosanitary products become extremely important, as well as the effect caused by them in the coffee quality. The objective of this work was to verify the influence of different methods of controlling fungal diseases in coffee plant on the grain quality of parchment and floater coffee. Trials were carried out in 2002/2003 and 2003/2004. The experimental design was the randomized complete block design subdivided into plots, using four replications, in a $2 \times 3 \times 2$ factorial structure, involving two harvests, three fungicide treatments (Ópera ${ }^{\circledR}$ systemic fungicide, Cobox ${ }^{\circledR}$ cupric fungicide, and non-treated control), and two kinds of processing, parchment and floaters. The evaluation of the quality of the grains was performed through chemical analyses: titrable acidity, $\mathrm{pH}$, leaching of potassium, and electrical conductivity. The results showed that the fungicide treatments just affect the leaching of potassium in floater coffee, in which Cobox ${ }^{\circledR}$ presented superior effect. In both processing methods studied the second year presented better electrical conductivity and better leaching of potassium in floater coffee. In the first year the parchment coffee presented superior effect for the titrable acidity.
\end{abstract}

Index terms: Coffea arabica L., quality, management.

(Recebido em 26 de abril de 2006 e aprovado em 10 de julho de 2008)

Para consolidação do sucesso econômico e da sustentabilidade das atividades cafeeiras, são fundamentais, em um modelo tecnológico de produção, ações pontuais que contemplem, em especial, a melhoria constante da qualidade do produto e a justa remuneração

do mesmo. As pesquisas têm demonstrado que a utilização de técnicas adequadas na condução da lavoura cafeeira é fator primordial para a produção de bebidas de qualidade.

Um fator de extrema importância e que tem ocasionado grandes prejuízos econômicos é o manejo

\footnotetext{
${ }^{1}$ Artigo extraído da dissertação de mestrado do primeiro autor apresentada a Universidade Federal de Lavras/ UFLA - CP 3037 - 37200000 - Lavras MG- Engenharia de Alimentos.

${ }^{2}$ Eng. . - Agr. ำ Ms em Ciência dos Alimentos pela Universiadade Federal de Lavras (UFLA).

${ }^{3}$ Professora Dra. do Departamento de Ciência dos Alimentos da UFLA.

${ }^{4}$ Professor Dr. do Departamento de Engenharia da UFLA.

${ }^{5}$ Eng.. Agr. a Dr Pesquisadora da Empresa de Pesquisa Agropecuária de Minas Gerais.

${ }^{6}$ Engenheiro Agrônomo Ms.
} 
inadequado de doenças foliares. A gravidade das doenças está relacionada a diversos fatores como clima, planta e manejo cultural utilizado. Perdas na qualidade são observadas no aspecto do produto, o que pode prejudicar sua comercialização, e ou reduzir a produção (Chaves \& Zambolim, 1985).

Dentre as doenças que ocorrem no cafeeiro (Coffea arabica L.) estão a ferrugem (Hemileia vastatrix Berk. \& Br.), mais importante doença desde sua identificação no Brasil e a cercosporiose (Cercospora coffeicola Berk \& Cooke), tida como doença secundária até pouco tempo, mas que se destaca pelo grande prejuízo causado. Ambas podem ser consideradas como as principais responsáveis pelo alto custo e queda na produtividade da cultura (Carvalho \& Chalfoun, 1998).

Mais recentemente, várias pesquisas têm mostrado que o nível de produção das plantas é mais um fator que determina um maior ou menor grau de infecção do cafeeiro pela ferrugem. (Carvalho \& Chalfoun, 1998). Segundo Souza (1996), já se observa uma tendência de utilização de medidas alternativas de controle, como aplicação de fungicidas sistêmicos via foliar, como triadimenol e cyproconazole, associados ou não aos fungicidas cúpricos, e aplicação da mistura fungicida/inseticida triadimenol + dissulfoton via solo, no entanto, ainda com baixos índices de substituição do sistema tradicional, utilizando-se exclusivamente o sistema preventivo com os fungicidas cúpricos. Também o uso de produtos protetores e/ou sistêmicos visando ao controle da ferrugem torna-se de grande importância para um controle mais efetivo dessa doença, com benefícios na preservação das folhas do cafeeiro (Cunha et al., 2001).

Freitas et al. (2003) constataram uma porcentagem de infecção por cercosporiose de $16 \%$ com a utilização de triazóis. No entanto, a utilização do triazol combinado à estrubirulina ocasionou um índice de infecção de 7,7\% no melhor tratamento.

Em lavouras adultas, a cercosporiose promove maturação acelerada, com aumento de grãos chochos e mal granados acarretando perdas no rendimento (coco/ beneficiado) e na qualidade quanto ao tipo e bebida do café (Matiello, 1997). A utilização de produtos fitossanitários que interrompam o ciclo da doença e a agressividade com que esse fungo atinge os frutos torna-se cada vez mais importante quando se pensa em qualidade de bebida.

O café, por apresentar mais de uma florada, proporciona numa mesma planta frutos em diferentes fases de maturação, chumbinho, verde, verde-cana, cereja, passa e seco. Em razão desta característica, é importante que a colheita seja efetuada quando a maioria dos frutos se encontra no estádio cereja, no qual são obtidas bebidas de melhor qualidade. Isso se explica pelo fato de ser o estádio cereja a fase correspondente ao ponto ideal de maturação dos frutos, no qual a casca, a polpa e as sementes encontram-se com a composição química adequada para proporcionar o máximo de qualidade (Carvalho et al., 1997). A permanência prolongada de frutos secos nos cafeeiros ou no solo pode possibilitar a ocorrência de fermentações e infestações microbianas, originando cafés de qualidade inferior quanto aos aspectos físicos e sensoriais (Meireles, 1990).

Teixeira (1979) relacionou os seguintes cuidados, na ocasião da colheita: deve ser iniciada quando a maioria dos frutos estiver madura e antes que se inicie a queda de frutos secos; evitar a incidência de grãos ardidos e pretos, que são resultantes da permanência prolongada dos frutos na árvore; evitar ao máximo a colheita de grãos verdes; efetuar a separação dos frutos em vários estágios de maturação, com o auxílio de lavadores e separadores, evitando-se uma matéria-prima heterogênea.

Os pesquisadores desse setor, como os membros da Organização Internacional do Café (OIC), enfatizam a necessidade de estudos no Brasil sobre a caracterização química dos grãos e a identificação de compostos prejudiciais à qualidade (Fernandes et al., 2001). Diante dos fatos, objetivou-se, com este trabalho, estudar a qualidade dos grãos de café cereja descascado e bóia procedentes de tratamentos fungicidas, em duas safras agrícolas.

As avaliações da qualidade dos grãos, por meio das análises químicas, foram realizadas no Pólo de Tecnologia em Qualidade do Café e no Departamento de Ciência dos Alimentos da Universidade Federal de Lavras (UFLA), na cidade de Lavras, MG.

As variações médias de temperatura e precipitação pluviométrica para os dois anos de ensaio estão apresentadas nas Figuras 1 e 2, e foram registrados pela Estação Climatológica Principal de Lavras, MG, e fornecidas pelo setor de Agroclimatologia do Departamento de Engenharia da UFLA.

$\mathrm{O}$ delineamento experimental utilizado foi o inteiramente casualizado com parcelas subdivididas, utilizando-se quatro repetições, em esquema fatorial 2 × 3 x 2 , compreendendo duas safras, três tratamentos fungicidas, e dois tipos de processamento, cereja descascado e bóia. As parcelas foram submetidas a aplicações com três tipos de tratamentos, fungicida sistêmico com ingrediente ativo pyraclostrobin + epoxiconazole, nome comercial Ópera ${ }^{\circledR}$, fungicida de contato, nome comercial Cobox ${ }^{\circledR}$ e testemunha não tratada com fungicidas. 


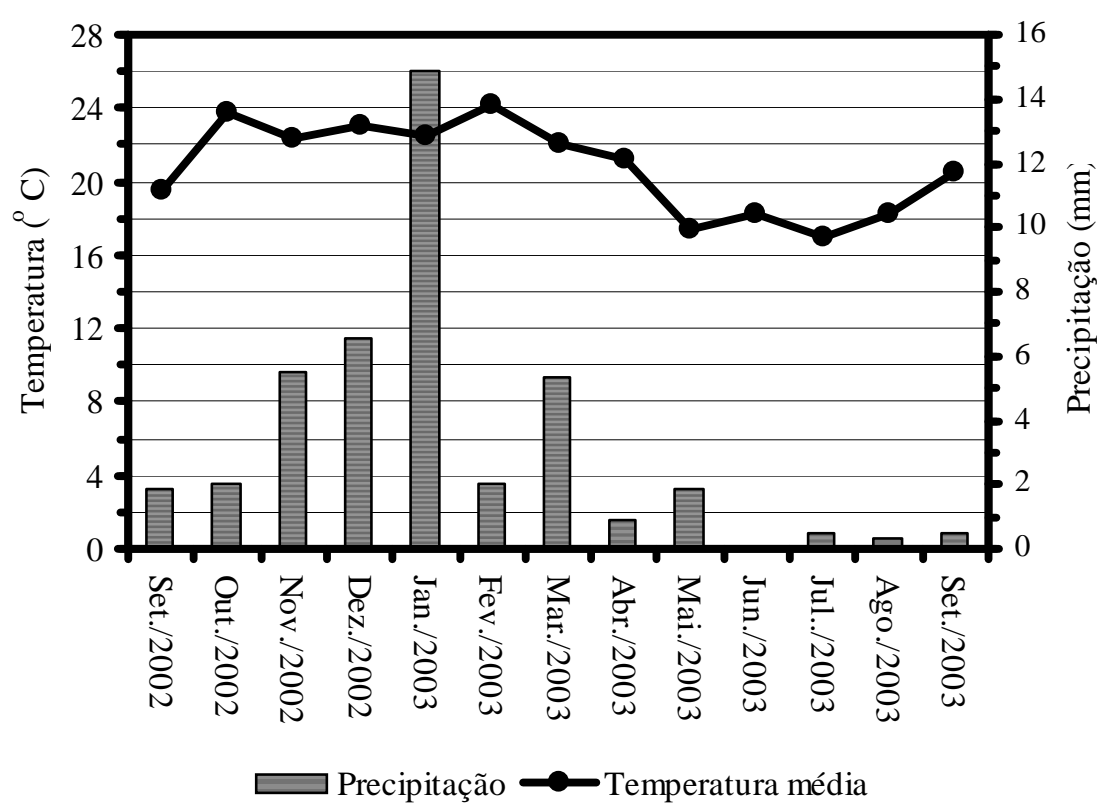

Figura 1 - Dados referentes a variação da temperatura média do ar e precipitação média diária coletada de setembro de 2002 a setembro de 2003. UFLA. (Fonte: Estação Climatológica de Lavras).

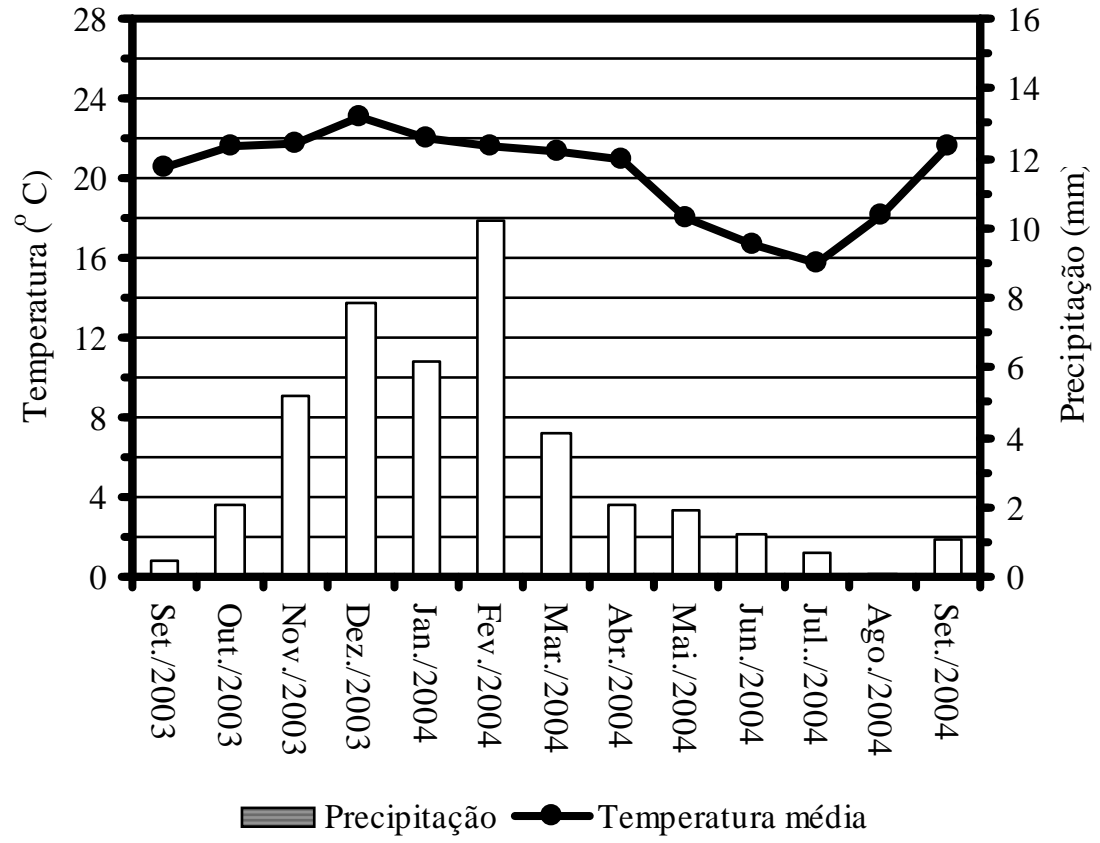

Figura 2 - Dados referentes a variação da temperatura média do ar e precipitação média diária coletada de setembro de 2003 a setembro de 2004. UFLA. (Fonte: Estação Climatológica de Lavras).

Foram utilizados grãos da espécie Coffea arabica L. provenientes de lavoura de café da cultivar Catuaí 99, implantada no ano de 1999. A fase de campo foi realizada durante duas safras consecutivas, nos anos agrícolas 2002/ 03 e 2003/04, tendo como parcelas 120 plantas, 4 ruas com 30 plantas cada, em espaçamento adensado 2,0 x 0,60 m, 
das quais foram consideradas como parcela útil as 40 plantas centrais.

As aplicações foliares dos fungicidas foram realizadas nas datas recomendadas pelos fabricantes, com acompanhamento técnico dos mesmos, utilizando-se um pulverizador turbo atomizador. Foram realizadas três pulverizações do fungicida cúprico, espaçadas de 30 dias, e duas pulverizações do fungicida sistêmico, espaçadas de 45 dias, de forma que a primeira e última pulverização coincidissem entre os tratamentos. Para o fungicida cúprico, aplicou-se a dosagem de $3 \mathrm{~kg} \mathrm{ha}^{-1}$ para cada uma das pulverizações e, para o sistêmico, 1,5 1 ha $^{-1} \mathrm{e} 1,01 \mathrm{ha}^{-1}$ na primeira e segunda pulverização, respectivamente, utilizando-se $4501 \mathrm{ha}^{-1}$ de calda. Durante todo o período de condução do experimento, as lavouras foram acompanhadas pelos técnicos envolvidos, visando ao monitoramento do nível de infecção das doenças.

Após a colheita, realizada manualmente em um único dia, foi avaliado o volume total colhido em cada parcela, sendo os frutos oriundos da colheita por derriça no pano levados imediatamente para o setor de Cafeicultura do Departamento de Agricultura da UFLA, onde foram processados por via úmida, eliminando-se os frutos verdes e separando-se as porções café cereja e bóia. Os frutos colhidos em cada parcela foram submetidos à secagem de terreiro de alvenaria até, aproximadamente, $12 \%$ b.u de umidade, sendo, posteriormente, analisados quimicamente. As parcelas foram aleatorizadas no citado terreiro.

$\mathrm{Na}$ tentativa de se eliminar possíveis erros decorrentes desta variabilidade, os frutos colhidos em cada uma das parcelas foram separados em verde, bóia e cereja, dos quais somente os frutos bóia e cereja, colhidos por derriça no pano, foram analisados separadamente.

A acidez foi determinada por titulação com $\mathrm{NaOH}$ 0,1 N, de acordo com técnica descrita pela AOAC (1990) e expressa em ml de $\mathrm{NaOH} 0,1 \mathrm{~N}$ por 100 gramas de amostra. A partir do mesmo extrato, o $\mathrm{pH}$ foi medido utilizando-se peagâmetro. A determinação da quantidade de potássio lixiviado foi realizada em fotômetro de chama após 3,5 horas de embebição dos grãos, segundo metodologia proposta por Prete (1992). Os resultados foram expressos em ppm. Determinou-se a condutividade elétrica, segundo metodologia proposta por Prete (1992). Os resultados foram expressos em $\mu \mathrm{S} \mathrm{cm} \mathrm{cm}^{-1} \mathrm{~g}^{-1}$.

Os tratamentos fungicidas e estes, dentro de cada ano, não foram significativos para a variável acidez titulável total, tanto para o café cereja descascado, como para o café bóia. Observa-se, pelas Tabelas 1 e 2, que os valores médios desta variável para as amostras de cafés cereja descascado e bóia analisadas, respectivamente, diferiram significativamente entre si $(\mathrm{P}<0,05)$, para os dois anos de ensaio estudados.
Tabela 1 - Valores médios de acidez titulável total $(\mathrm{mL}$ de $\mathrm{NaOH}$ 0,1N/100g) dos grãos de café cereja descascado, obtidos no ensaio qualidade de café e métodos de controle de doenças fúngicas, anos agrícolas 2002/03 e 2003/04. UFLA, Lavras, MG, 2006.

\begin{tabular}{ccc}
\hline Ano & $1(2002 / 03)$ & $2(2003 / 04)$ \\
\hline Médias & $7,174 \mathrm{~b}$ & $6,399 \mathrm{a}$ \\
\hline
\end{tabular}

Médias seguidas pela mesma letra não diferem entre si, pelo teste de Tukey, a 5\% de probabilidade.

Tabela 2 - Valores médios de acidez titulável total ( $\mathrm{mL}$ de $\mathrm{NaOH}$ 0,1N/100g) dos grãos de café bóia, obtidos no ensaio qualidade de café e métodos de controle de doenças fúngicas, anos agrícolas 2002/03 e 2003/04. UFLA, Lavras, MG, 2006.

\begin{tabular}{ccc}
\hline Ano & $1(2002 / 03)$ & $2(2003 / 04)$ \\
\hline Médias & $6,927 \mathrm{~b}$ & $6,689 \mathrm{a}$ \\
\hline
\end{tabular}

Médias seguidas pela mesma letra não diferem entre si, pelo teste de Tukey, a 5\% de probabilidade.

Ocorreram diferenças significativas $(\mathrm{P}<0,05)$ de um ano para o outro, nos valores de acidez titulável total das amostras de café cereja descascado e bóia de 0,775 e 0,238 $\mathrm{mL}$ de $\mathrm{NaOH} 0,1 \mathrm{~N} / 100 \mathrm{~g}$, respectivamente, o que correspondeu a $12,11 \%$ e $3,56 \%$ a mais para a safra de 2002/03. Esse fato, apesar da ausência de resposta significativa entre os tratamentos fungicidas, poderia estar ocorrendo em função do efeito residual e do acúmulo dos produtos utilizados, contribuindo para a redução significativa dos valores de acidez titulável total.

Outro fator de relevância a ser considerado é o de que o fator ano agrícola sofreu efeitos referentes às condições climáticas muito diferentes, conforme mostram as Figuras 1 e 2. Observa-se que a distribuição pluviométrica foi bastante desuniforme no segundo ano de ensaio. $\mathrm{Na}$ safra 2002/03, foram registrados picos de chuva entre meses alternados a partir do mês de janeiro. No primeiro ano, houve menor índice de chuva durante a época da colheita (junho e julho), o que proporciona condições desfavoráveis ao desenvolvimento de patógenos que poderiam comprometer a qualidade dos frutos na planta. Em relação à temperatura, observa-se pouca variação entre os mesmos meses dos anos estudados, e temperaturas amenas, variando de 16 (julho de 2004) a $24^{\circ} \mathrm{C}$ (fevereiro de 2003).

Vários pesquisadores têm buscado nas análises químicas um auxilio para a classificação sensorial do café e 
muitos trabalhos de pesquisa têm demonstrado que frutos de café de pior qualidade apresentam maiores valores de acidez titulável total (Pimenta, 1995; Pimenta \& Vilela, 2002). Segundo Pimenta (2003), a acidez titulável em grãos de café pode variar de acordo com os níveis de fermentações que ocorrem nos grãos e também com os diferentes estádios de maturação dos mesmos, podendo também servir como suporte para auxiliar na avaliação da qualidade de bebida do café.

Para a variável pH, não foi observado qualquer efeito significativo dos tratamentos fungicidas e do ano agrícola, independente do tipo de café, a $5 \%$ de probabilidade $(\mathrm{P}<0,05)$. Logo, os métodos de controle de doenças fúngicas utilizados neste trabalho não alteraram os resultados de $\mathrm{pH}$ para as amostras de café analisadas.

Para os valores de condutividade elétrica, somente a fonte de variação ano agrícola (Tabela 3) foi afetada significativamente $(\mathrm{P}<0,05)$ e, exclusivamente, para o café cereja descascado, a $1 \%$ de probabilidade. Por outro lado, para as amostras referentes ao café bóia, o teste $\mathrm{F}$ detectou significância $(\mathrm{P}<0,05)$ a $1 \%$ de probabilidade para o fator ano nas duas análises (Tabela 4).

Tabela 3 - Valores médios de condutividade elétrica $\left(\mu \mathrm{S} . \mathrm{cm}^{-1} \cdot \mathrm{g}^{-1}\right)$ dos grãos de café cereja descascado, obtidos no ensaio qualidade de café e métodos de controle de doenças fúngicas, anos agrícolas 2002/03 e 2003/04. UFLA, Lavras, MG, 2006.

\begin{tabular}{cll}
\hline Ano & $1(2003)$ & $2(2004)$ \\
\hline Médias & $148,34 \mathrm{a}$ & $192,71 \mathrm{~b}$ \\
\hline
\end{tabular}

Médias seguidas pela mesma letra não diferem entre si, pelo teste de Tukey, a 5\% de probabilidade.

Tabela 4 - Valores médios de condutividade elétrica $\left(\mu \mathrm{S} . \mathrm{cm}^{-1} \cdot \mathrm{g}^{-1}\right)$ e lixiviação de íons potássio $(\mathrm{ppm})$ dos grãos de café bóia, obtidos no ensaio qualidade de café e métodos de controle de doenças fúngicas, anos agrícolas 2002/03 e 2003/04. UFLA, Lavras, MG, 2006.

\begin{tabular}{ccc}
\hline Médias & Ano 1 (2003) & Ano 2 (2004) \\
\hline Condutiv. elétrica & $152,50 \mathrm{a}$ & $198,15 \mathrm{~b}$ \\
\hline $\begin{array}{c}\text { Lixiviação de } \\
\text { potássio }\end{array}$ & $46,77 \mathrm{a}$ & $68,87 \mathrm{~b}$ \\
\hline
\end{tabular}

Médias seguidas pela mesma letra não diferem entre si, pelo teste de Tukey, a 5\% de probabilidade.
O teste Tukey detectou diferenças significativas entre os dois anos de ensaio experimental para o café cereja descascado somente para a variável condutividade elétrica, tendo os maiores valores sido detectados no segundo ano de controle fúngico (Tabela 3 ). Já para o café bóia, foi detectada diferença tanto de condutividade elétrica como de lixiviação de potássio (Tabelas 4 e 5), nos quais os maiores valores, assim como para o café cereja descascado, são observados no segundo ano de ensaio (2003/04).

Tabela 5 - Valores médios de lixiviação de íons potássio (ppm) dos grãos de café bóia obtidos no ensaio qualidade de café e métodos de controle de doenças fúngicas, anos agrícolas 2002/03 e 2003/04. UFLA, Lavras, MG, 2006.

\begin{tabular}{cl}
\hline Tratamentos & Médias \\
\hline Testemunha & $64,57 \mathrm{C}$ \\
Ópera $^{\circledR}$ & $59,90 \mathrm{~B}$ \\
Cobox $^{\circledR}$ & $49,00 \mathrm{~A}$ \\
\hline
\end{tabular}

Médias seguidas pela mesma letra não diferem entre si, pelo teste de Tukey, a 5\% de probabilidade.

Os valores de lixiviação de íons potássio e, consequentemente, de condutividade elétrica, dependem da integridade do sistema de membranas e de sua capacidade de se reorganizar durante a reidratação dos grãos. Dentro deste conceito, grãos com injúrias ocasionadas por agentes patogênicos, tais como insetos, danos mecânicos e secagem mal conduzida apresentam maiores valores de lixiviação de potássio e condutividade elétrica comparados com grãos sadios (Prete, 1992; Prete et al., 1999; Silva, 2003).

Porém, os maiores valores no segundo ano, observados para estas duas variáveis, podem ser atribuídos a variações climáticas já mencionadas durante os anos, por serem experimentos realizados em épocas diferentes. Vilela (1997) relata que até mesmo em regiões aptas ao cultivo do café, por ser uma cultura considerada perene, as condições adversas de clima em todo o ano na forma de precipitações, variação da temperatura e umidade relativa do ar, durante as fases de floração, frutificação e amadurecimento, podem provocar maturação muito desuniforme. Isso provoca elevado percentual de frutos verdes na colheita e fermentação indesejável nos frutos maduros, resultando em perda da qualidade antes mesmo da colheita.

Os valores de condutividade elétrica e lixiviação de íons potássio encontrados neste trabalho estão acima dos 
relatados por Silva (2003), que estudou a qualidade de 15 amostras de cafés produzidas na faixa de altitude de 720 a 920m, no Sul de Minas, onde se encontra o município de Nepomuceno. Esse autor observou teores entre 67,55 e $152,25 \mu \mathrm{S} \mathrm{cm}^{-1} \mathrm{~g}^{-1}$ e 21,42 a 59,61 ppm, para os teores de condutividade e de íons potássio, respectivamente.

Embora diversas pesquisas venham se esforçando em relacionar características químicas com qualidade de café (Lopes et al., 2000; Pinto et al., 2002; Ribeiro et al., 2003; Silva et al., 2004), não foi possível ainda se estabelecer um protocolo de classificação de qualidade, em função da complexidade de compostos que existem nos grãos de café.

Observa-se efeito significativo dos métodos de controle fungicidas sobre os teores médios de íons potássio lixiviados. O fungicida Cobox ${ }^{\circledR}$, à base de cobre, apresentou os menores valores de lixiviação, diferenciandose estatisticamente dos demais tratamentos, a $1 \%$ de probabilidade. $\mathrm{O}$ fungicida Ópera ${ }^{\circledR}$ apresentou resultado intermediário ao fungicida Cobox ${ }^{\circledR}$ e a testemunha, sem tratamento fungicida.

Os valores de lixiviação de íons potássio encontrados neste trabalho são bem mais elevados do que os verificados por Prete (1992), que foram de 42,49 ppm no líquido/g de amostra para grãos colhidos verdes e 18,30 ppm para grãos colhidos cerejas. No tratamento com o fungicida Ópera ${ }^{\circledR}$, verificam-se valores próximos aos encontrados por Pimenta (1995), que observou a maior lixiviação em grãos de cafés colhidos verdes (59,19 ppm). Valores próximos também foram obtidos por Lopes et al. (2000) trabalhando com diferentes cultivares de café. No entanto, os valores conferidos neste trabalho indicam a probabilidade de ocorrência de classes de bebida de padrões inferiores.

$\mathrm{Na}$ avaliação de cafés classificados como bebida mole, apenas mole e extritamente mole, Pinto et al. (2002) observaram valores para lixiviação de potássio entre 28,51 e 32,8 ppm. Nos cafés classificados como bebida rio e riada, a lixiviação de potássio apresentou valores de 40,32 e 36,28 ppm, respectivamente.

Diante dos fatos, conclui-se que os tratamentos afetaram apenas a lixiviação de potássio, no qual o Cobox® apresentou efeito superior aos demais. Em ambos os processamentos estudados, o segundo ano de ensaio apresentou maior condutividade elétrica, e quando considerado o café bóia, maior lixiviação de potássio. $\mathrm{O}$ resultados apontam ainda que, no primeiro ano de ensaio o café cereja descascado apresentou efeito superior para a acidez titulável.

\section{REFERÊNCIAS BIBLIOGRÁFICAS}

ASSOCIATION OF OFFICIAL ANALYTICAL CHEMISTS. Oficial methods of the association of oficial analytical chemists. 15.ed. Washington, DC, 1990. 684p.

CARVALHO, V.D. de; CHAGAS, S.J.R.; SOUZA, S.M.Z.

Fatores que afetam a qualidade do café. Informe Agropecuário, Belo Horizonte, v.18, n.187, p.5-20, 1997.

CARVALHO, V.L.; CHALFOUN, S.M. Manejo integrado das principais doenças do cafeeiro. Informe agropecuário, Belo Horizonte, n.193, p.27-35, 1998.

CHAVES, G.M.; ZAMBOLIM, L. Conceito de doenças em plantas. Informe Agropecuário, Belo Horizonte, v.2, n.122, p.6-7, 1985.

CUNHA, R.L. et al. Efeito de tratamentos químicos no controle da ferrugem (Hemileia vastatrix) e na preservação do enfolhamento do cafeeiro. In: SIMPÓSIO DE PESQUISA CAFEEIRA DO SUL DE MINAS, 2., 2001, Lavras, MG. Anais... Lavras: UFLA, 2001. p.182-185.

FERNANDES, S.M. et al. Polifenóis, sólidos solúveis totais, açúcares totais, redutores e não redutores em grãos de café arábica e conilon. In: SIMPÓSIO DE PESQUISA DOS CAFÉS DO BRASIL, 2., 2001, Vitória, ES. Anais... Vitória: IBC, 2001. p.101.

FREITAS, J.L.P. et al. Uso de novos fungicidas no controle simultâneo da ferrugem (Hemileia vastatrix) e cercospora (Cercospora coffeicola) no cafeeiro. In: CONGRESSO BRASILEIRO DE PESQUISAS

CAFEEIRAS, 29., 2003, Araxá, MG. Anais... Rio de Janeiro: MAPA-Procafé, 2003. p.89.

LOPES, L.M.V.; PEREIRA, R.G.F.A.; MENDES, A.N.G.; VILELA, E.R.; CARVALHO, V.D. Avaliação da qualidade de grãos de diferentes cultivares de cafeeiro (Coffea arabica L.). Revista Brasileira de Armazenamento, Viçosa, v.1, p.3-8, 2000.

MATIELLO, J.B. Gosto do meu cafezal. Rio de Janeiro: [s.n.], 1997. 262p.

MEIRELES, A.M.A. Ocorrência e controle da microflora associada aos frutos de café (Coffea arabica $L$.) provenientes de diferentes localidades do estado de Minas Gerais. 1990. 71p. Dissertação (Mestrado em Fitotecnia)Escola Superior de Agricultura de Lavras, Lavras, 1990. 
PIMENTA, C.J. Qualidade do café (Coffea arabica L.) originado de diferentes frutos colhidos de quatro estádios de maturação. 1995. 94p. Dissertação (Mestrado em Ciência dos Alimentos)-Universidade Federal de Lavras, Lavras, 1995.

PIMENTA, C.J. Qualidade do café. Lavras: UFLA, 2003. $304 p$.

PIMENTA, C.J.; VILELA, E.R. Qualidade do café (Coffea arabica $\mathrm{L}$.) colhido em sete épocas diferentes na região de Lavras-MG. Ciência e Agrotecnologia, Lavras, v.26, p.1481-1491, dez. 2002. Edição especial.

PINTO, N.A.V.D.; FERNANDES, S.M.R. do N.; GIRANDA, R.G.F.A.; CARVALHO, V.D. de. Avaliação de componentes químicos de padrões de bebida para preparo do café expresso. Ciência e Agrotecnologia, Lavras, v.26, n.4, p.826-829, jul./ago. 2002.

PRETE, C.E.C. Condutividade elétrica do exsudato de grãos de café (Coffea arabica L.) e sua relação com a qualidade da bebida. 1992. 125p. Tese (Doutorado em Agronomia)-Escola Superior de Agricultura Luiz de Queiroz, Piracicaba, 1992.

PRETE, C.E.C. et al. Condutividade elétrica de exsudatos de grãos de café colhidos em diferentes estádios de maturação. In: SEMINÁRIO INTERNACIONAL SOBRE BIOTECNOLOGIA NA AGROINDÚSTRIA CAFEEIRA,
3., 1999, Londrina, PR. Anais... Londrina: UFRP-IAPAR, 1999. p.475-477.

RIBEIRO, D.M.; BORÉM, F.M.; ANDRADE, E.T. de; ROSA, S.; DELIZETY, V.F. da. Taxa de redução de água do café cereja descascado em função da temperatura da massa, fluxo de ar e período de pré-secagem. Revista Brasileira de Armazenamento, Viçosa, v.27, n.7, p.94-107, 2003.

SILVA, R.F. da. Qualidade do café cereja descascado produzido na Região Sul de Minas Gerais. 2003. 97p. Dissertação (Mestrado em Ciência dos Alimentos)Universidade Federal de Lavras, Lavras, 2003.

SILVA, R.F.; PEREIRA, R.G.F.A.; BORÉM, F.M.; MUNIZ, J.A. Qualidade do café cereja descascado produzido na região sul de Minas Gerais. Ciência e Agrotecnologia, Lavras, v.28, n.6, p.1367-1375, nov./dez. 2004.

SOUZA, S.C. de. O café (Coffea arabica L.) na região Sul de Minas Gerais: relação da qualidade com fatores ambientais, estruturais e tecnológicos. 1996. 171p. Tese (Doutorado em Fitotecnia)-Universidade Federal de Lavras, Lavras, 1996.

TEIXEIRA, A.A. Colheita, preparo, armazenamento e classificação do café. Campinas: Coordenadoria de Assistência Técnica Integral, 1979.

VILELA, E.R. Secagem e qualidade do café. Informe Agropecuário, Belo Horizonte, v.18, n.187, p.55-63, 1997. 